\title{
Contrataciones públicas socialmente responsables: la necesidad de reconsiderar el potencial de la contratación pública en la consecución de objetivos sociales
}

\section{María Burzaco Samper}

\section{RESUMEN}

La relevancia de los fondos públicos dedicados a la contratación hace imprescindible una reflexión sobre la viabilidad de alcanzar fines de interés general que trasciendan el objeto propio de cada contrato. La Unión Europea ha aprobado recientemente un paquete legislativo -las conocidas como Directivas de contratación de cuarta generación- que comporta el tránsito hacia la contratación pública estratégica e intenta profundizar en las posibilidades de las "contrataciones públicas socialmente responsables" en cumplimiento de los objetivos establecidos en la Estrategia Europa 2020. Este potencial de la contratación conoce, sin embargo, dificultades importantes atendiendo no sólo a la normativa, sino a la interpretación que de determinados principios se ha hecho por parte de los órganos jurisdiccionales, administrativos y consultivos. Teniendo en cuenta que estamos inmersos en pleno proceso de reforma, se examinarán los avances y problemas de las consideraciones sociales en la normativa que está por venir.

PALABRAS CLAVE: Contratación pública, cláusulas sociales, Economía social, Estrategia Europa 2020.

CLAVES ECONLIT: A13, K12, K23, H57, H72, L31.

Cómo citar este artículo / How to cite this article: BURZACO SAMPER, M. (2016): "Contrataciones

públicas socialmente responsables: la necesidad de reconsiderar el potencial de la contratación pública en la consecución de objetivos sociales", CIRIEC-España, Revista de Economía Pública, Social y Cooperativa, 86, 281-310.

Correspondencia: María Burzaco Samper, profesora Propia Adjunta de Derecho Administrativo, Universidad Pontificia Comillas-ICADE. E-mail: mburzaco@icade.comillas.edu. 


\section{EXPANDED ABSTRACT}

\section{Socially responsible public procurement: the need to reconsider the power of public procurement for achieving social objectives}

In 2014, the European Union approved a set of secondary legislation - known as the fourth generation of procurement directives - which involves the transition towards strategic procurement and attempts to go deeper into the possibilities of "socially responsible procurement". In a nutshell, it talks about the massive quantity of public funds for procurement (In Spain it is around $20 \%$ of the GDP) and fulfilling the ambitious objectives of the Europe 2020 Strategy. This strategy establishes three main priorities: a) intelligent growth through more efficient investments in education, investigation and innovation; b) sustainable growth driving a low carbon economy and fighting against global warming; and c) inclusive growth, highlighting job creation and poverty reduction.

In relation to this strategy, the European Commission has issued "50 proposals for improving our work, business and exchanges with one another" and "Twelve levers to booost growth and strengthen confidence". One of these twelve priorities is a revised and modernised regulatory framework for public contracts to achieve, among other aims, environmentally sustainable, socially responsible and innovative procurement.

However, the procurement potential has encountered some difficulties with certain elements of the procurement requirements and especially with the interpretation of the contractual principles. These are central, but most are skewed towards the purely economic aspect of procurement. As a result, social and environmental aspects are placed at different levels, but properly linked to the main subject matter of each contract. In this view, "the most advantageous economic proposal" barely serves the general interests attached to the contract and creates a clash between the main subject matter and the main goal of the general interest.

These difficulties are reflected in the high number of consultations and conflicts resolved in the courts: the social clauses have a place in several areas of the contract but in practice, all of them present almost insoluble problems in their "link to the subject matter of the contract" and as regards the procurement principles (free competition, equality and non-discrimination). This is what happens when their inclusion has been demanded as a criterion for adjudication of the contract and even, to a lesser extent, as a special condition for execution. At this moment, the present study has found many resolutions of consultative agencies in matters of procurement as well as court rulings that show the difficulties: in a word, the "ubiquity" of social clauses has become a problem of "location". 
The Public Administrations that are more sensitive towards incorporating social elements in their contractual activity have ended up testing different legal formulas, through imaginative definitions of the contract, for instance, or, the riskiest, passing legislation they require their procurement staff to stand by. All the possibilities devised pose legal validity problems, as shown in several judicial proceedings.

Our proposal calls for taking advantage of the moment of regulatory reform obliged by the 2014 Directives to advance the role of procurement in achieving objectives of general interest and social character. Moreover, we consider that both the Europe 2020 strategy and the Directives require that changes be projected in the following areas:

1. From a negative point of view (i.e. determining consequences for everyone who violates social (or other) postulates), the warranty of the State, in the execution of public contracts, is required to ensure that economic operators comply with their legal obligations in environmental, social or labour matters.

2. The active or positive level is more complex because we do not see many differences between current and previous directives. The recitals of Directive 2014/24 / EU show a wish to advance the inclusion of social criteria, but there are problems in their mandatory use and their generalization to all public contracting activity. In Spain the draft bill incorporates some interesting innovations: the list of tiebreakers include insertion companies, non-profit entities, companies that incorporate measures favouring the extension of gender equality. They have also introduced new options in the special conditions of implementation of a social nature and are firmly committed to supporting small and medium enterprises. In any case, the most important obstacle is the requirement of linkage to the subject matter of the contract, although there is a certain flexibility in the new rules to the extent that it seems not to be required to be "direct". We believe that the solution to the problem is to accept that social clauses and public contracts serve different purposes, in a natural process, and are not called unfailingly to interbreed. That is why, in line with some doctrines, we advocate proposals that have already been made for a comprehensive vision that understands that recruiting is not an objective in itself, but an instrument at the service of public needs of a very different character. The principle of efficiency requires linking the use of public funds (obviously also intended procurement) to the satisfaction of the general interest, a generic goal which materializes in multiple purposes (social, ecological, innovation and research, ...). 
From the foregoing we put forward some concrete proposals: a) clear identification of the area where social clauses should be included in the contract; b) removing the rigidity of the direct link with the subject matter of the contract and interpreting this linkage in a broader and more flexible way; c) requiring the objectives to include evaluation of the impact on recruitment. The latter proposal is also linked to the impact analysis, an essential ingredient of the so-called smart regulation which is also part of the Europe 2020 Strategy.

KEY WORDS: Governmental Accounting, Local Authorities, Setting of Accounting Standards Process in the Public Sector, Accounting Reform. 


\section{CONTRATACIONES PÚBLICAS SOCIALMENTE RESPONSABLES: LA NECESIDAD DE RECONSIDERAR EL POTENCIAL DE LA CONTRATACIÓN PÚBLICA EN LA CONSECUCIÓN DE OBJETIVOS SOCIALES}

\section{1.- Reflexión de partida}

Este trabajo debe comenzar poniendo de manifiesto que nos encontramos a la espera de la enésima reforma de le legislación contractual pública, tal y como impone la trasposición de las Directivas de contratación de febrero de 20141. Se ha dicho que esta cuarta generación de Directivas representa el tránsito hacia una contratación pública estratégica (GIMENO FELIÚ, 2014:16), algo que, por lo demás, venía reclamándose desde tiempo atrás. No en vano el Libro verde sobre la modernización de la política de contratación pública de la UE [COM (2011) 0015] demandaba la utilización estratégica de la contratación pública en respuesta a los nuevos desafíos y objetivos trazados por la Estrategia Europa 20202.

El planteamiento inicial de este trabajo toma en consideración dos elementos que a prioriactúan en planos distintos: por un lado, la magnitud de las cifras en las que se mueve la contratación pública y que, en el caso español, se cifra en torno a un 18\% del PIB3; por otro, el principio esencial de funcionamiento de las Administraciones Públicas establecido en el art. 103.1 CE, conforme al cual, aquellas "sirve(n) con objetividad los intereses generales". El interés general como concepto jurídico indeterminado que constituye auténtica piedra angular del Derecho Administrativo debe encontrar traslación en los intereses públicos concretos que han de guiar la actuación de las Administraciones Públicas y constituyen el fin de las diferentes potestades que éstas tienen atribuidas.

La relevancia de los fondos públicos dedicados a la contratación conduce inevitablemente a preguntarse si no es factible que, a través de la misma, puedan alcanzarse fines que trasciendan el objeto propio de cada contrato 4 . Ello comporta considerar la contratación como medio de intervención eco-

1.- Nos referimos a las siguientes Directivas, todas ellas publicadas en el Diario Oficial de la Unión Europea (en adelante DOUE) de 28 de marzo de 2014:

- Directiva 2014/23/UE del Parlamento Europeo y del Consejo de 26 de febrero de 2014 relativa a la adjudicación de contratos de concesión. DOUE núm. L 94/1.

- Directiva 2014/24/UE del Parlamento Europeo y del Consejo de 26 de febrero de 2014 sobre contratación pública y por la que se deroga la Directiva 2004/18/CE. DOUE núm. L 94/65.

- Directiva 2014/25/UE del Parlamento Europeo y del Consejo de 26 de febrero de 2014 relativa a la contratación por entidades que operan en los sectores del agua, la energía, los transportes y los servicios postales y por la que se deroga la Directiva 2004/17/CE. DOUE núm. L 94/243.

- En relación con el concreto aspecto de la factura electrónica, véase Directiva 2014/55/UE del Parlamento Europeo y del Consejo de 16 de abril de 2014 relativa a la facturación electrónica de la contratación pública. DOUE núm. L 133/1, de 6 de mayo de 2014.

Sin restar importancia a ninguna de ellas, la más relevante para nosotros es la 2014/24/UE que deberá ser objeto de transposición al ordenamiento jurídico español antes del 18 de abril de 2016, excepción hecha de ciertas previsiones del art. 22 Directiva 2014/24/UE-acerca de normas aplicables a las comunicaciones-, en el que se señala fecha posterior.

2.- COMISIÓN EUROPEA. Comunicación de la Comisión de 3 de marzo de 2010 «Europa 2020, una estrategia para un crecimiento inteligente, sostenible e integrador" [COM (2010) 2020 final]. Las remisiones a este texto que se lleven a cabo a partir de ahora emplearán la siguiente referencia: EE2020.

3.- Los datos pueden consultarse en COMISIÓN NACIONAL DE LOS MERCADOS Y DE LA COMPETENCIA (CNMC).

PRO/CNMC/001/15: Análisis de la contratación pública en España: oportunidades de mejora desde el punto de vista de la competencia (informe aprobado el 5 de febrero de 2015), en especial pp. 3 y 4. Disponible en:

http://www.cnmc.es/Portals/0/Notas\%20de\%20prensa/201502_Informe_ContratacionPublica.pdf

4.- BERNAL BLAY, 2008: en especial, 212 y ss y bibliografía allí citada. 
nómico y social; una idea verbalizada con fundamento por voces reputadas e instituciones de reconocida importancia en el ámbito de la contratación pública:

"...la contratación pública no puede ser considerada como un fin en sí mismo sino que debe ser visualizada como una potestad o herramienta jurídica al servicio de los poderes públicos para el cumplimiento efectivo de sus fines o sus políticas públicas. Es decir, la contratación puede -y debe, diríaser una técnica que permitiera conseguir objetivos sociales, ambientales o de investigación, en la convicción de que los mismos comportan una adecuada comprensión de cómo deben canalizarse los fondos públicos.

Esto significa que (...) los contratos públicos no constituyen exclusivamente un medio de abastecerse de materias primas o de servicios en condiciones más ventajosas para el Estado, sino que, en la actualidad a través de la contratación pública, los poderes públicos realizan una política de intervención en la vida económica, social y política del país, lo que convierte a la contratación pública en un ámbito de actividad a través del cual poder orientar determinados comportamientos de los agentes económicos intervinientes (...)"5.

No obstante lo certero del comentario trascrito, el misma plantea determinadas dificultades atendiendo tanto a la normativa ${ }^{6}$, como a los propios principios de la contratación.

\section{2.- Estrategia Europa 2020 y contratación pública socialmente responsable}

El potencial de los fondos públicos invertidos en contratos para la consecución de objetivos socioeconómicos relevantes, no puede desgajarse de la Estrategia Europa 2020. Sin ánimo de hacer un recorrido exhaustivo por la misma, hemos de recordar que se articula en torno a tres ejes que constituyen sus prioridades esenciales: a) un crecimiento inteligente, a través de inversiones más eficaces en educación, investigación e innovación; b) sostenible, impulsando una economía baja en carbono y luchando contra el cambio climático; y c) integrador, subrayando la creación de empleo y la reducción de la pobreza.

5.- GIMENO FELIÚ, 2013: 3; y 2014: 39 y ss. Recalca asimismo el carácter instrumental de la contratación y su potencial papel en la consecución de objetivos sociales, ambientales y de investigación el Informe de la Junta Consultiva de Contratación Administrativa de Aragón 17/2008, de 21 de julio (apartado II). Asunto: "Especialidades de contratación en Servicios Sociales: Convenios de financiación".

6.- Sin perjuicio de estar en pleno momento de transición hacia una nueva normativa, al momento de escribir este trabajo está en vigor el Real Decreto Legislativo 3/2011, de 14 de noviembre, por el que se aprueba el Texto refundido de la Ley de Contratos del Sector Público (en adelante TRLCSP). Por lo demás se cuenta ya con un Borrador de Anteproyecto de Ley de Contratos del Sector Público (fechado el 17 de abril de 2015). En lo sucesivo, Anteproyecto. Disponible en:

http://www.minhap.gob.es/Documentacion/Publico/NormativaDoctrina/Proyectos/Borrador\%20Anteproyecto\%20de\%20Ley\%20de\%20Contrat os\%20del\%20Sector\%20P\%C3\%BAblico-\%2017\%20abril\%202015.pdf 


\section{CONTRATACIONES PÚBLICAS SOCIALMENTE RESPONSABLES: LA NECESIDAD DE RECONSIDERAR EL POTENCIAL DE LA CONTRATACIÓN PÚBLICA EN LA CONSECUCIÓN DE OBJETIVOS SOCIALES}

Lejos de actuar de manera aislada, las tres prioridades "se refuerzan mutuamente y ofrecen una imagen de la economía social de mercado de Europa para el siglo XXl"7; una conexión que demuestran las iniciativas emblemáticas en que aquellas se concretan.

Enlazando con la EE2020, la propia Comisión Europea plantea "Cincuenta propuestas para trabajar, emprender y comerciar todos juntos"8 y aunque éstas aluden en diversos puntos a la contratación pública, su protagonismo se intensifica posteriormente constituyéndose en una de doce prioridades para estimular el crecimiento y reforzar la confianza9:

"Revisión y modernización del marco normativo de los contratos públicos para llegar a una política equilibrada que preste apoyo a una demanda de bienes, servicios y obras que sean respetuosos del medio ambiente, socialmente responsables e innovadores. La revisión, además, deberá ofrecer a las autoridades adjudicadoras unos procedimientos más sencillos y flexibles y habrá de garantizar un acceso más fácil a las empresas, particularmente a las PYME" (Medida clave núm. 12) ${ }^{10}$

Cumpliendo dicho cometido de revisión normativa las nuevas Directivas -y singularmente la Directiva 2014/24/UE- hacen referencias frecuentes a la EE2020 y, recalcando el papel clave que la contratación pública ha de jugar en ésta, exige revisar y modernizar las normas relativas a contratación pública "a fin de incrementar la eficiencia del gasto público, facilitando en particular la participación de las pequeñas y medianas empresas (PYME) en la contratación pública, y de permitir que los contratantes utilicen mejor la contratación pública en apoyo de objetivos sociales comunes" (Considerando 2). La Unión Europea se sitúa así en línea con las llamadas "contrataciones públicas socialmente responsables", operaciones de contratación que atienden a una serie de aspectos sociales: oportunidades de empleo, trabajo digno, cumplimiento con los derechos sociales y laborales, inclusión social (abarcando las personas con discapacidad), igualdad de oportunidades, diseño de accesibilidad para todos, consideración de los criterios de sostenibilidad, incluidas las cuestiones de comercio ético y un cumplimiento voluntario más amplio de la responsabilidad social de las empresas (RSE) ${ }^{11}$.

7.- EE2020, apartado 2: 12.

8.- COMISIÓN EUROPEA. Hacia un Acta del Mercado Único. Por una economía social de mercado altamente competitiva. Cincuenta propuestas para trabajar, emprender y comerciar mejor todos juntos. COM (2010) 608 final. 27 de octubre de 2010.

9.- COMISIÓN EUROPEA. Acta del Mercado Único. Doce prioridades para estimular el crecimiento y reforzar la confianza. "Juntos por un nuevo crecimiento". COM (2011) 206 final. \{SEC (2011) 467 final\}

10.- Negrita y cursiva en el original. Últ. documento citado: 20-21. Esta medida se motiva después, aunque ciertamente de manera vaga y excesivamente genérica refiriéndose a que las "necesidades del sector público ofrecen buenas oportunidades para aumentar la demanda de bienes, servicios y obras que, además de respetuosos con el medio ambiente, sean socialmente responsables e innovadores" o la posibilidad de que los contratos públicos puedan servir "de instrumento para potenciar el desarrollo de un mercado interior más ecológico, social e innovador" (p. 21).

11.- COMISIÓN EUROPEA. Adquisiciones sociales. Una guía para considerar aspectos sociales en las contrataciones públicas, octubre 2010: p. 7. Disponible en: http://rscat.gencat.cat/web/.content/04_-_ambit_administracio/documents/arxius/adquisiciones_sociales.pdf

MEDINA ARNÁIZ (2012: 3-4) anota que la expresión viene a comprender los conceptos de "compra social" (que considera aspectos como la lucha contra el desempleo, calidad en el empleo, contratación de personas discapacitadas, políticas de género,...) y "compra ética" (referida al cumplimiento de valores y estándares éticos establecidos en las convenciones internacionales). 
En cualquier caso la concreción ulterior de estos propósitos es más bien tímida y debe reconocerse que los aspectos sociales no han merecido la misma atención que otros elementos ${ }^{12}$, razón que posiblemente explique sus todavía discretos resultados.

\section{3.- Los aspectos sociales en la contratación pública: su contenido y posibles ubicaciones}

\section{1. ¿De qué se habla cuando se alude a criterios sociales?}

La generalidad e indeterminación de la adjetivación "social" hace pertinente enunciar, siquiera brevemente, los contenidos que han pretendido encajarse en la misma:

a) Empleo y condiciones laborales. Es posiblemente el más común de los referentes al considerar criterios sociales, aunque abarca en realidad cuestiones distintas: desde fines trabados al incremento de la empleabilidad ${ }^{13}$-bien en términos generales, bien relacionada con colectivos específicos con dificultades superiores de acceso al empleo-, hasta las condiciones de los trabajadores de las empresas licitadoras y adjudicatarias de los contratos públicos ${ }^{14}$, pasando por la estabilidad en el empleo. En suma, en similar sentido al que hallaremos en el art. 118.1 TRLCSP cuando establece la posibilidad de condiciones especiales de ejecución de impronta social.

b) Políticas de igualdad de género ${ }^{15}$, que, por lo demás, se traban muchas veces a la esfera del mercado de trabajo ya por las mayores dificultades de las mujeres en el acceso al empleo, ya por las diferencias en las propias condiciones de trabajo.

c) Apoyo a colectivos en riesgo de exclusión, que cuenta con algunas medidas específicas que después examinaremos.

12.- Este hecho ha sido puesto de manifiesto por el propio Parlamento Europeo, en su Resolución de 25 de octubre de 2011, sobre modernización de la contratación pública (2011/2048(INI) (2013/C 131 E/03), DOUE núm. C131 E/25. En ella se evidencia que ni el Libro Verde ni la Guía para considerar aspectos sociales en las contrataciones públicas son de la suficiente utilidad.

13.- BERNETE GARCÍA (2013: 86), entiende que las cláusulas sociales son el "instrumento más eficaz con el que cuenta hoy en día la Administración para fomentar empleo".

14.- Realiza un exhaustivo estudio sobre esta cuestión MARTíNEZ FONS, 2009. Contamos asimismo con un número apreciable de informes de órganos consultivos: por citar sólo algunos, Informe de la Junta Consultiva de Contratación Administrativa del Estado (JCCA) 14/2010, de 23 de julio. Asunto: "Concepto de servicios que llevan aparejado el ejercicio de autoridad y posibilidad de incluir en el pliegos de cláusulas administrativas particulares la referencia a las obligaciones derivadas de las normas que regulan la prevención de riesgos laborales"; IJCCA Islas Baleares 4/02, de 27 de junio de 2002 sobre Decret de mesures en la contratació administrativa de la Comunitat Autònoma de les Illes Balears de suport a l'estabilitati a la quoalitat de l'ocupació.

Más recientemente, IJCCA de la Generalitat de Catalunya 18/2014, de 17 de diciembre, sobre la posibilidad de incluir medidas de promoción de la salud en los contratos del sector público (en referencia a aspectos relativos a la prevención de riesgos laborales, el fomento de hábitos saludables y la promoción del desarrollo personal y organizacional por parte de las empresas licitadoras).

15.- Sobre las cláusulas de discriminación positiva y su correcta traslación a la contratación pública, LESMES ZABALEGUI, 2005: 53-86; y SÁNCHEZ MORÓN, 2012: 7-16. 


\section{CONTRATACIONES PÚBLICAS SOCIALMENTE RESPONSABLES: LA NECESIDAD DE RECONSIDERAR EL POTENCIAL DE LA CONTRATACIÓN PÚBLICA EN LA CONSECUCIÓN DE OBJETIVOS SOCIALES}

d) Comercio justo, entendido como "relación de intercambio comercial basada en el diálogo, la transparencia y el respeto, que busca una mayor equidad en el comercio internacional" (COM (2009) 215 final) ${ }^{16}$.

\subsection{Los aspectos sociales en los procedimientos de contratación: su (problemá- tica) ubicación y alcance}

\section{A) Sobre la ubicación de los criterios sociales}

Las buenas intenciones sobre la incorporación de cláusulas sociales se tornan, sin embargo, menos halagüeñas en su aplicación práctica. El modo en que la contratación pública opera y, sobre todo, el juego de los principios de la contratación vienen a suponer un recorte importante en la virtualidad de aquellas. De ello da buena muestra la abundante casuística ligada a los conflictos y consultas en la materia, que viene a revelar la imposibilidad de tratar este tema de manera lineal.

Así las cosas, procede un análisis ordenado del distinto campo de juego que las cláusulas sociales tienen en los procedimientos de contratación, distinguiendo las diversas parcelas eventualmente afectadas:

a) La centralidad de los principios de contratación y su absoluto protagonismo en la resolución de conflictos es algo fuera de cuestión ${ }^{17}$. Sin embargo no es menos cierto que dentro de los mismos los aspectos sociales tienen escasa cabida, a salvo de las derivaciones indirectas que pueda alumbrar una interpretación más compleja (y creativa).

En este punto la reforma normativa no aporta importantes novedades, excepción hecha del principio de integridad (que aparece en el art. 1 del Anteproyecto) y nace de la lógica preocupación por erradicar la corrupción del mundo de la contratación pública ${ }^{18}$.

16.- COMISIÓN EUROPEA. "Contribución al desarrollo sostenible: el papel del comercio justo y de los sistemas no gubernamentales de garantía de la sostenibilidad comercial’. COM (2009) 215 final (5 de mayo de 2009).

Sobre el comercio justo en la contratación pública y sus problemas, MEDINA ARNÁIZ, 2012: 15-20; de la misma autora, 2015.

17.- Dichos principios se sitúan en el pórtico de la ley (TRLCSP), cuyo art. 1, primer párrafo establece: "La presente Ley tiene por objeto regular la contratación del sector público, a fin de garantizar que la misma se ajusta a los principios de libertad de acceso a las licitaciones, publicidad y transparencia de los procedimientos, y no discriminación e igualdad de trato entre los candidatos, y de asegurar, en conexión con el objetivo de estabilidad presupuestaria y control del gasto, una eficiente utilización de los fondos destinados a la realización de obras, la adquisición de bienes y la contratación de servicios mediante la exigencia de la definición previa de las necesidades a satisfacer, la salvaguarda de la libre competencia y la selección de la oferta económicamente más ventajosa (...)".

Estos mismos principios son los señalados en la adjudicación de contratos por parte de entes, organismos y entidades del sector público que no tengan carácter de poderes adjudicadores (art. 192.1 TRLCSP)

18.- Sobre el principio de integridad, OECD, Integrity in Public Procurement. Good practice from A to Z 2009. Disponible en: http://www.oecd.org/development/effectiveness/38588964.pdf

Traducción al español en SÁNCHEZ GIL (trad.), 2009. http://www.crisisycontratacionpublica.org/wp-content/uploads/2014/11/La-integridaden-la-contrataci\%C3\%B3n-p\%C3\%BAblica.

En dicho informe se pone de relieve que "la contratación pública es considerada la actividad gubernativa más vulnerable a la corrupción" (últ. op. cit.: 17), lo que unido a las cifras económicas que se mueven en dicho ámbito ha propiciado el protagonismo de este principio de nuevo cuño o las prevenciones relativas a los conflictos de intereses (Considerando 16 y art. 24 Directiva 2014/24/UE).

El Dictamen 8/2015 del Consejo Económico y Social (CES) sobre el Anteproyecto resalta también esta cuestión y pide mayor concreción y claridad en la redacción del art. 64 relativo a la "Lucha contra la corrupción y prevención de los conflictos de intereses" (pp. 10-11 y 16-17). http://www.ces.es/documents/10180/2394234/Dic082015.pdf 
b) La problemática más virulenta sobre la inclusión de los criterios sociales en la contratación se ha producido cuando se ha pretendido su incorporación como criterios de adjudicación. Recordemos que éstos constituyen los elementos que, definidos previamente en los pliegos de cláusulas administrativas particulares (PCAP) que rigen el contrato, sirven de parámetros de valoración de las ofertas presentadas por los licitadores.

El art. 150 TRLCSP mantiene la pauta de normas anteriores aportando un listado de criterios que, en realidad, es meramente ejemplificativo. En este sentido, la auténtica regla de oro y parámetro de legalidad de cualquier criterio de adjudicación de un contrato pasa por el cumplimiento de una serie de requisitos cuya exigencia encuentra sus raíces en la jurisprudencia del TJUE, a saber: a) vinculación directa con el objeto del contrato; b) que no confieran a la entidad adjudicadora una libertad incondicional de elección; c) que se mencionen expresamente en los PCAP o en el anuncio de licitación; y d) que respeten los principios fundamentales de la contratación (transparencia, no discriminación, concurrencia competitiva) ${ }^{19}$.

Aunque las fronteras no siempre son claras, estos requisitos han permitido vetar algunos criterios20: así ha ocurrido con aspectos tales como el porcentaje de trabajadores fijos de una empresa ${ }^{21}$ o cláusulas de discriminación positiva en favor de determinados colectivos con problemas de inserción laboral (discapacitados 22 , parados de larga duración $23, \ldots$ )

Ateniéndonos al factor social, destacaremos del extenso listado del citado art. 150 TRLCSP las características "vinculadas con la satisfacción de exigencias sociales que respondan a necesidades, definidas en las especificaciones del contrato, propias de las categorías de población especialmente desfavorecidas a las que pertenezcan los usuarios o beneficiarios de las prestaciones a contratar". Si una lectura inicial de la fórmula no propicia una optimista interpretación del mismo, menos alentadora es aún la realizada por la Junta Consultiva de Contratación Administrativa del Estado que

19.- SSTJUE de 17 de septiembre de 2002 (Concordia Bus Finland Oy Ab contra Helsingin kaupunki y HKL-Bussiliikenne), C-513/99, apartado 69; y de 4 de diciembre de 2003 (EVN AG y Wienstrom GmbH contra Republik Österreich) C-448/01, apartados 33 y 34. En similar línea, art. 67.4 Directiva 2014/14/UE.

20.- Sobre esta cuestión, BERNAL BLAY, 2011: 142-143. La jurisprudencia comunitaria es también relevante en este aspecto y se advierte en ella un tránsito hacia posiciones más restrictivas. Un análisis más detenido de esta jurisprudencia, su evolución y contradicciones puede encontrarse en GALLEGO CÓRCOLES, 2011; MEDINA ARNÁIZ, 2012: 5 y ss.

21.- Esta cuestión llegó a instancias europeas, con el resultado que pone de manifiesto la STS (Sala $3^{a}$ ) de 27 de junio de 2006 (RJ 2006/6108): el conflicto se suscitó con ocasión de la impugnación de determinados preceptos del Decreto 213/1998, de 17 de diciembre, de la Comunidad Autónoma de Madrid que primaba a las empresas con mayor porcentaje de trabajadores fijos. La STS de 30 de mayo de 2003 consideró conforme a Derecho tales preceptos al estimar que no encerraban situaciones discriminatorias como alegaba la recurrente. No obstante este fallo judicial, las asociaciones de empresarios de la Construcción habían denunciado la situación ante la Comisión Europea, que en su Dictamen de 21 de diciembre de 2001 examina las medidas destinadas a apoyar la estabilidad del empleo y las encaminadas a favorecer la integración social de los minusválidos establecidas en el Decreto madrileño. Tal dictamen mantiene que "tales criterios pueden aceptarse como cláusulas contractuales que imponen condiciones de ejecución de los contratos pero que no pueden servir en ningún caso para evaluar la oferta más ventajosa económicamente y que tales criterios deberían considerarse en su caso para apreciar la capacidad técnica de la empresa en la fase de selección de los contratistas, pero no en el momento de determinar la oferta más ventajosa económicamente". Un relato más extenso de este caso puede encontrarse en nuestro trabajo BURZACO SAMPER, 2010: 175-177.

22.- IJCCA 1/05, de 11 de marzo de 2005. Asunto: "Interpretación y aplicación de la preferencia para trabajadores minusválidos prevista en la disposición adicional octava, apartado 1 de la Ley de Contratos de las Administraciones Públicas".

23.- IJCCA 44/04, de 12 de noviembre de 2004. Asunto: "Posibilidad de inclusión de cláusulas de discriminación positiva en los pliegos".

CIRIEC-España, Revista de Economía Pública, Social y Cooperativa

ISSN: 0213-8093

№ $86 / 2016$, pp. $281-310$ 


\section{CONTRATACIONES PÚBLICAS SOCIALMENTE RESPONSABLES: LA NECESIDAD DE RECONSIDERAR EL POTENCIAL DE LA CONTRATACIÓN PÚBLICA EN LA CONSECUCIÓN DE OBJETIVOS SOCIALES}

ha precisado que "este supuesto no abarca cualquier consideración de carácter social sino sólo aqueIlos contratos en que las prestaciones a contratar vayan destinadas a categorías de población especialmente desfavorecidas"24. Esta concepción reduccionista prácticamente veda las posibilidades de configurar criterios de adjudicación impregnados de fines sociales y desprende un criticable halo de marginalidad 25 .

c) En contraste con esta limitada visión, la ley contempla determinadas previsiones cuya intención última es primar en la contratación a empresas comprometidas con trabajadores en situación de dificultad para su integración en el mercado de trabajo. Singularmente significativa es la Disposición Adicional $4^{a}$ TRLCSP que otorga preferencia a empresas que tengan en su plantilla personas con discapacidad o en situación de exclusión social y con entidades sin ánimo de lucro (y cumpliendo los requisitos establecidos en el mencionado precepto) ${ }^{26}$, aunque siempre partiendo de un empate en la valoración de las ofertas. Estas situaciones de empate nos conducen a lo que algunos han dado en llamar criterios adicionales y que, finalmente, actúan como elemento para dirimir aquellas.

La controversia sobre estos criterios adicionales se ha centrado en si las previsiones legales eran o no susceptibles de ampliación a través de los pliegos, esto es, si los PCAP pueden o no establecer criterios de desempate distintos de los contemplados en la ley, cuestión que ha recibido una respuesta dispar27. Hemos de señalar, no obstante, que la jurisprudencia ha demostrado más sensibilidad y audacia en algunos casos: así, en STS de 17 de julio de $2012^{28}$ que, confirmando la sentencia recurrida en casación, declara válido el criterio de desempate en la adjudicación del contrato que atendía al porcentaje de personal femenino fijo en la empresa por estimar que el principio de igualdad actúa de manera transversal en el ordenamiento jurídico, lo que se traduce "por lo que hace a las Administraciones públicas, [en que] el objetivo o meta de la igualdad de hombres y mujeres podrá ser perseguido en la totalidad de sus actividades, esto es, cualquiera que sea el instrumento formal en

24.- IJCCA 3/09, de 25 de septiembre de 2009. Asunto: "Posibilidad de establecer como condición de ejecución del contrato la utilización de un determinado porcentaje de personas desempleadas que se encuentren inscritas en las oficinas de empleo de una localidad y de establecer un criterio de adjudicación del contrato que consistiese en la valoración del compromiso de emplear en su ejecución personas desempleados inscritas en una determinada oficina de empleo. Ámbito de aplicación de criterios sociales".

25.- Esta redacción obedece a la sugerencia del Consejo de Estado en su Dictamen 514/2006, de 25 de mayo, ya que, en opinión del órgano consultivo, la mera mención a "características medioambientales o sociales" que recogía el Anteproyecto de Ley no se acomodaba a la Directiva 2004/18/UE. Como apunta ZUÑIGA RIAL (2008: 89), el margen de operatividad que dejan estas limitaciones "[hacen] prácticamente inviable su aplicación en aquellos contratos excluidos del marco de la acción administrativa social o asistencial".

26. - Dicha DA $4^{a}$ TRLCSP se compone de diversos apartados en los que se contempla la posible preferencia para: 1) Empresas públicas o privadas que, en el momento de acreditar su solvencia técnica, tengan en su plantilla un número de trabajadores con discapacidad superior al 2\%; 2) empresas de inserción (con remisión a la regulación y requisitos de la Ley 44/2007, de 13 de diciembre, para la regulación del régimen de las empresas de inserción); 3) entidades sin ánimo de lucro, con personalidad jurídica, siempre que su finalidad o actividad tenga relación directa con el objeto del contrato, según resulte de sus respectivos estatutos o reglas fundacionales y figuren inscritas en el correspondiente registro oficial (este supuesto en relación con contratos relativos a prestaciones de carácter social o asistencial); y 4) entidades reconocidas como Organizaciones de Comercio Justo (respecto de contratos que tengan como objeto productos en los que exista alternativa de Comercio Justo).

27.- Puede notarse cierta evolución hacia la flexibilidad en la incorporación de criterios de desempate: véanse, por ejemplo, los citados IJCCA 44/04 y 1/05 (rígidos en su planteamiento e interpretación de las previsiones normativas); en contraste, Resolución del Tribunal Central de Recursos Contractuales (TACRC) núm. 002/2014, de 10 de enero de 2014 [recursos núm. 798/2013 y 919/2013], FJ 8º que permite que los PCAP contemplen un orden de prelación en los criterios de desempate, siendo algunos de ellos ajenos a los previstos en la DA $4^{a} T R L C S P$.

28. - STS (Sala 3ª, Sección $7^{a}$ ) de 17 de julio de 2012; recurso núm. 5377/2009. EDJ 2013/3212.

Esta Sentencia viene a confirmar en casación la STSJ Extremadura núm. 708/2009, de 16 de julio de 2009 (recurso núm. 74/2008; EDJ 2009/166258).

CIRIEC-España, Revista de Economía Pública, Social y Cooperativa 
que estas se manifiesten (procedimiento, acto o contrato), cualquiera que sea su contenido (regulador, de servicio público, fomento, policía, etc.) y cualquiera que sea la materia sectorial a que esté referida" (FJ 6 ${ }^{\circ}$ ). Una sentencia de contenido similar29 fue criticada por MEDINA ARNÁIZ (2010), al entender que el factor género no puede actuar como criterio de adjudicación. Ciertamente el planteamiento de la sentencia es confuso por cuanto parece dar a entender la conformidad a Derecho de la discriminación positiva siempre partiendo de situaciones previas de empate (por tanto, en igual línea a la resolución judicial confirmada por el TS); confusión que viene dada por que, en realidad, no era éste el objeto del debate jurídico sino el hecho de que el pliego recogiera como criterio de adjudicación -y no como criterio adicional de desempate- el número de mujeres en plantilla.

Curiosamente los problemas de la DA $4^{\mathrm{a}}$ TRLCSP no se quedan únicamente en su eventual carácter cerrado 0 abierto, sino en su propia suficiencia caso de que los pliegos se limiten a una remisión a dicho precepto. Esta cuestión fue objeto del IJCCA 14/13, en el que se hace notar que el mismo contiene distintos criterios, siendo por tanto necesario que los PCAP incluyan los elementos diferenciadores. Ello comporta que una mera remisión a la ley es, en la práctica, inaplicable si no hay ulterior determinación en los pliegos. La situación descrita se complica aún más si tenemos en cuenta que un empate sin criterios que diriman el mismo carece de salida en la ley, salvado el caso de que la adjudicación se sirva únicamente del factor precio (lo que se conoce tradicionalmente como subasta); supuesto que se resuelve mediante sorteo (art. 87.2 RCAP30). Este procedimiento, sin embargo, no se ha considerado válido cuando son varios los criterios de adjudicación del contrato (concurso) ${ }^{31}$.

En todo caso la virtualidad de estos criterios adicionales es siempre relativa dada la infrecuencia de los empates, lo que, sin duda, mitiga sobremanera la eventual ventaja pretendida por la previsión legal32.

d) Distinta a la anterior es la reserva de contratos prevista en la Disposición Adicional $5^{\text {a }}$ TRLCSP; precepto que permite reservar bien la participación en los procedimientos de adjudicación de contratos, bien su ejecución, a determinados tipos de empresas o entidades ${ }^{33}$.

29.- STSJ Extremadura núm. 535/2009, de 16 de junio de 2009 (recurso núm. 249/2008; EDJ 2009/120936) Públicas.

30.- Real Decreto 1098/2001, de 12 de octubre, por el que se aprueba el Reglamento General de la Ley de Contratos de las Administraciones

31.- Véase en este sentido, el interesante conflicto resuelto por el TACRC mediante Resolución 159/2011, de 8 de junio (recurso núm. 119/2011) que fue anulada por la SAN de 7 de marzo de 2013 (recurso núm. 387/2013. EDJ 2013/24253), al entender ésta que, siendo los pliegos la ley del contrato y no previendo aquellos criterio de desempate, no procedía la aplicación analógica del art. 87.2 RCAP al estar la adjudicación basada en criterios distintos y no exclusivamente en el precio.

Curiosamente, en Resolución 031/2014, de 17 de enero (recurso núm. 868/2013), posterior a la resolución y sentencia ahora mencionada, el TACRC mantiene que el sorteo es el sistema idóneo cuando los pliegos no determinan el criterio de desempate de entre los indicados en la DA $4^{a}$ TRLCSP; también en este sentido IJCCA Catalunya 7/2014, de 11 de abril. Asunto: "Resolución de empates en las puntuaciones obtenidas por las ofertas de las empresas licitadoras".

32.- ZUÑIGA RIAL, 2008: 78; RODRÍGUEZ MUÑOZ, 2011: 15.

33.- Distingue ambas figuras el IJCCA 59/08, de 31 de marzo de 2009. Asunto: "Diferencia entre el contenido normativo de la disposición adicional sexta, apartado 3, sobre consideración del número de personas minusválidas integradas en las plantillas de personal de las empresas licitadoras, y la disposición adicional séptima, sobre reserva de contratos a favor de empresas cuya finalidad es la promoción de personas con discapacidad que no puedan ejercer una actividad profesional en condiciones normales". 


\section{CONTRATACIONES PÚBLICAS SOCIALMENTE RESPONSABLES: LA NECESIDAD DE RECONSIDERAR EL POTENCIAL DE LA CONTRATACIÓN PÚBLICA EN LA CONSECUCIÓN DE OBJETIVOS SOCIALES}

En este punto la reciente Ley $31 / 2015$, de 9 de septiembre 34 ha introducido un cambio relevante: así, la redacción original de la mencionada DA $5^{\text {a }}$ TRLCSP permitía la reserva a Centros especiales de empleo, cuando al menos el $70 \%$ de los trabajadores fueran personas con discapacidad que no pudieran ejercer una actividad profesional en condiciones normales por la índole o gravedad de sus deficiencias. Por el contrario, la redacción actual del precepto se ha visto significativamente ampliada al incluir también a las empresas de inserción, rebajar el porcentaje mencionado al $30 \%$ y contemplar la posible reserva de lotes, amén de darle un carácter aparentemente obligatorio inexistente en el texto original. Respecto de esta última cuestión el precepto establece que mediante Acuerdo del Consejo de Ministros o a través de los órganos autonómicos y locales competentes en sus respectivos ámbitos "se fijarán porcentajes mínimos de reserva del derecho a participar en los procedimientos de adjudicación de determinados contratos o de determinados lotes de los mismos a Centros Especiales de Empleo y a empresas de inserción (...) o un porcentaje mínimo de reserva de la ejecución de estos contratos en el marco de programas de empleo protegido (...)"(DA 5 a apartado 1 TRLCSP). Esta nueva redacción encierra una suerte de deber de reserva que contrasta claramente con el "podrá reservarse" que iniciaba el precepto antes de esta reforma de septiembre de 2015.

Indudablemente cualquier reserva de contratos supone una limitación a la concurrencia que, sin embargo, se justifica precisamente desde la necesidad de garantizar la igualdad de oportunidades y la inserción social de determinados colectivos. Se trata, en suma, de una posibilidad que intenta reequilibrar situaciones de desigualdad y ofrecer la oportunidad de contratar con las Administraciones Públicas a empresas u organizaciones cuya posición en cualquier licitación ordinaria es de clara inferioridad. La Directiva 2014/24/UE da cuenta de cómo estas razones abonan la pertinencia de dichas reservas ${ }^{35}$, estableciéndolas en su art. 20.

e) El campo de juego más favorable a los aspectos sociales es el que ofrecen las llamadas condiciones especiales de ejecución (art. 118 TRLCSP). Esta expresión abarca las condiciones de corte sectorial dirigidas al cumplimiento de determinados intereses públicos en los ámbitos medioambiental y social. En concreto son las tendentes a promover "el empleo de personas con dificultades particulares de inserción en el mercado laboral, eliminar las desigualdades entre el hombre y la mujer en dicho mercado, combatir el paro, favorecer la formación en el lugar de trabajo, u otras finalidades que se establezcan con referencia a la estrategia coordinada para el empleo, definida en el art. 145 del Tratado de Funcionamiento de la Unión Europea, o garantizar el respeto a los derechos

\footnotetext{
34.- Ley 31/2015, de 9 de septiembre por la que se modifica y actualiza la normativa en materia de autoempleo y se adoptan medidas de fomento y promoción del trabajo autónomo y de la Economía Social. BOE núm. 217, de 10 de septiembre de 2015.

35.- En efecto, en el Considerando 36 Directiva 2014/24/UE podemos leer: "El empleo y la ocupación contribuyen a la integración en la sociedad y son elementos clave para garantizar la igualdad de oportunidades en beneficio de todos. En este contexto, los talleres protegidos pueden desempeñar un importante papel. Lo mismo puede decirse de otras empresas sociales cuyo objetivo principal es apoyar la integración social y profesional o la reintegración de personas discapacitadas o desfavorecidas, como los desempleados, los miembros de comunidades desfavorecidas u otros grupos que de algún modo están socialmente marginados. Sin embargo, en condiciones normales de competencia, estos talleres o empresas pueden tener dificultades para obtener contratos. Conviene, por tanto, disponer que los Estados miembros puedan reservar a este tipo de talleres o empresas el derecho a participar en los procedimientos de adjudicación de contratos públicos o de determinados lotes de los mismos o a reservar su ejecución en el marco de programas de empleo protegido".
} 
laborales básicos a lo largo de la cadena de producción mediante la exigencia del cumplimiento de las Convenciones fundamentales de la Organización Internacional del Trabajo".

No puede desconocerse que la incorporación de estas condiciones de ejecución sociales y ambientales planteó dudas iniciales que la Comisión Europea trató de aclarar mediante dos Comunicaciones interpretativas (2001/C333/07 y 2001/C333/08) en las que se analiza el juego de estos criterios en las distintas fases del contrato 36 .

Hoy en día parece haberse aceptado sin dificultad que el cauce más idóneo para la incorporación de cláusulas sociales son precisamente las condiciones especiales de ejecución, aunque algunos aspectos distan de estar cerrados. Así, y pese al impulso dado desde las distintas Administraciones Públicas, esta cuestión no ha estado exenta de conflictos fundamentalmente cuando la pretensión pasa por favorecer objetivos sociales de carácter local; situaciones en las que, casi invariablemente, las cláusulas se han apreciado como discriminatorias ${ }^{37}$.

\section{B) En cuanto al cauce formal oportuno para el establecimiento de cláusulas sociales}

La lectura de los aspectos tratados en el epígrafe anterior parece dar por sentada la falta de controversia sobre los PCAP como el cauce formal en el que tales criterios sociales se integran. Sin embargo la pretensión de que determinadas condiciones se incorporen preceptivamente a toda la actividad contractual de una Administración ha abierto nuevos conflictos y dudas de los que debemos dar cuenta.

Las primeras respuestas eran bastante claras sobre la no pertinencia de establecer con carácter obligatorio y para toda la actividad contractual de un órgano de contratación condiciones de este tipo (adviértase que estamos hablando de condiciones especiales de ejecución; obviamente la improcedencia como criterio de adjudicación era aún más nítida). La vinculación de las condiciones al objeto

36.- FERNÁNDEZ ASTUDILLO (2005: 235) resumió los dos requisitos fundamentales para el establecimiento de estas condiciones especiales de ejecución: 1) Vinculación directa con el objeto del contrato que se esté tramitando. De ello deriva: (i) que no se debe imponer con carácter general, a través de leyes, reglamentaciones y demás normas, la inclusión indiscriminada de determinados aspectos sociales o medioambientales; (ii) que el aspecto social y/o medioambiental incluido se fundamente en la naturaleza de la prestación objeto de esta contratación o, en su caso, a sus condiciones de ejecución.

2) Compatibilidad de los aspectos sociales y/o medioambientales con el Derecho Comunitario, sus libertades y principios.

Por evidentes razones de seguridad jurídica, el establecimiento de condiciones especiales ha de indicarse en el anuncio de licitación y en el pliego o en el contrato; exigencia de publicidad que se traba a los efectos que, de acuerdo con el art. 118.2 TRLCSP, pueden contemplar Ios pliegos en relación con aquellas, a saber: a) Establecer penalidades para el caso de incumplimiento de las condiciones especiales; b) atribuirles carácter de obligaciones contractuales esenciales a los efectos del art. $223 \mathrm{f}$ ) TRLCSP, esto es, aquellas cuyo incumplimiento constituye causa de resolución del contrato; c) caso de que el incumplimiento no se tipifique como causa de resolución, los pliegos o el contrato podrán considerarlo como infracción grave a los efectos del art. 60.2 e) TRLCSP, es decir, como una de las circunstancias que determinan la prohibición de contratar con las Administraciones Públicas.

37.- Vgr. IJCCA 3/09, respecto del establecimiento de una condición especial de ejecución que obligaba a utilizar un determinado porcentaje de personas desempleadas inscritas en la oficina de empleo de una concreta localidad. En la misma, sin embargo, se aclara que es "admisible el establecimiento de condiciones de ejecución que favorezcan la lucha contra el desempleo que no incurran en discriminación".

Asimismo IJCCA Aragón 6/2009, de 15 de abril, en relación con un pliego de cláusulas que primaba la generación de empleo en la Comarca de pertenencia del órgano de contratación.

CIRIEC-España, Revista de Economía Pública, Social y Cooperativa

ISSN: 0213-8093

№ $86 / 2016$, pp. $281-310$ 


\section{CONTRATACIONES PÚBLICAS SOCIALMENTE RESPONSABLES: LA NECESIDAD DE RECONSIDERAR EL POTENCIAL DE LA CONTRATACIÓN PÚBLICA EN LA CONSECUCIÓN DE OBJETIVOS SOCIALES}

del contrato se tornaba en un obstáculo, que sólo se salvaba bien convirtiendo la obligación en recomendación, bien sometiéndola a requisitos que, en la práctica, la dificultaban considerablemente 38 .

La trascendencia de esta cuestión es indudable por cuanto tiene consecuencias no sólo sobre el alcance de la misma -obligatoriedad o mera recomendación de cláusulas sociales- sino también sobre el instrumento formal adecuado para su establecimiento.

Precisamente este último asunto ha dado lugar a un debate jurídico que merece tratarse con un poco de detenimiento y que encuentra su mejor plasmación en la STSJ País Vasco núm. 344/2014, de 11 de julio de 201439. El conflicto se suscita en relación con la Instrucción del Consejo de Gobierno de la Diputación Foral de Bizkaia de 29 de octubre de 2013 sobre criterios de mantenimiento de las condiciones de trabajo y medidas de carácter social para su aplicación en los procedimientos de contratación 40 . Buena parte del debate jurídico se centra en la naturaleza jurídica de la Instrucción y su acomodo a las características de estas figuras de las instrucciones, órdenes de servicio, circulares internas... establecidas en el art. 21 de la Ley 30/1992, de 26 de noviembre, de Régimen Jurídico de las Administraciones Públicas y del Procedimiento Administrativo Común (LRJAP-PAC). El Tribunal entiende que la Instrucción foral excede de sus contornos propios (orientación de la actuación de los órganos subordinados), configurándose como auténtica norma reglamentaria, disposición de carácter general con efectos jurídicos ad extra. Como la sentencia explicita:

“(...) la Instrucción contiene (...) elementos de regulación destinados a terceros, a los contratistas, y elementos de regulación en tanto en cuanto que norma, innovando el ordenamiento, las consecuencias que la actuación de éstos va a producir a través de la creación de una nueva regulación conforme a la cual el contratista puede mantener las condiciones del contrato o de la oferta si renuncia a la aplicación de las consecuencias a las que está facultado por la reforma laboral o bien va a verlas alteradas si no lo hace. Los derechos y obligaciones de los terceros se ven afectados con la instrucción y se ven afectados en razón a que [la Diputación Foral] introduce una nueva regulación con incidencia directa en materia laboral pues el condicionado y desarrollo del contrato va a depender de las decisiones que se adopten en materia laboral por parte del contratista".

38.- Destaca en este sentido el IJCC Aragón 16/2014, de 1 de octubre que, en contestación a una consulta sobre el establecimiento de una condición especial de ejecución en virtud de la cual se obligue a las empresas adjudicatarias a no minorar las condiciones de trabajo (jornada, salario y mejoras sobre legislación laboral básica) de los trabajadores adscritos al contrato, establecía una serie de pautas a considerar:

a) Necesidad de acotar el ámbito de aplicación, por cuanto este tipo de cláusulas solo tienen sentido cuando se contratan prestaciones en las que el ingrediente económico fundamental venga del coste de la mano de obra o en las que se incorporen cláusulas de subrogación de trabajadores.

b) La inclusión de este tipo de cláusulas requieren tanto de la vinculación al objeto y tipología del contrato como de una evaluación previa que determine la idoneidad de su inclusión y, en su caso, su alcance temporal. Ello, finalmente, remite a una decisión del órgano de contratación en la valoración de las circunstancias de cada concreta licitación, salvo que el órgano competente dote del instrumento normativo adecuado que establezca su obligatoriedad o su recomendación.

c) Incorporación de los parámetros objetivos para determinar cuándo la obligación se entiende cumplida.

39.- Recurso núm. 777/2013. RJ 2014/697.

40.- BOB núm. 2018, de 14 de noviembre. 
No siendo, por lo demás, incardinable en el art. 118 TRLCSP (condiciones especiales de ejecución), la conclusión es obvia ya que las Diputaciones Forales carecen de competencia alguna en materia de legislación laboral.

Al término de esta fundamentación, esta misma resolución judicial recoge una afirmación que servirá de enlace con lo que analizaremos a continuación:

"La ampliación del contenido de los Pliegos debe hacerse a través de un auténtico reglamento en la medida en que no se limita a dar pautas de actuación a causa de la mera valoración, interpretación, de las normas sino que innova el ordenamiento, regula cómo deben actuar los distintos órganos de contratación creando nuevas obligaciones desarrollando varias normas, y afecta a terceros, a los contratistas $y$, en segundo lugar, no puede tener por objeto materias sobre las que la demandada carece de competencia como es la determinación de las condiciones de trabajo en las empresas" (FJ 3)

A este proceso -que ha tenido el lógico eco entre órganos que desempeñan su labor en el ámbito de la contratación pública ${ }^{41}$ - le han seguido otros con ciertas diferencias en cuanto a su contenido:

En conflictos posteriores, el propio TSJ País Vasco resuelve los recursos interpuestos contra la Norma Foral de las Juntas Generales de Gipuzkoa 4/2013, de 17 de julio, de incorporación de cláusulas sociales en los contratos de obras del Sector Público Foral42. Contrariamente a lo acontecido en el proceso anterior, el Tribunal entiende que estamos en este caso ante la aprobación de cláusulas generales que, con base en "quien puede lo más puede lo menos", pueden establecer normativamente las cláusulas sociales que hayan de regir la contratación de los órganos integrados en la Administración foral. Frente a los argumentos de la recurrente, dicha facultad de incorporar cláusulas generales de tipo social no constituye una innovación del ordenamiento jurídico -para lo que no tendría competencia en la materia-, sino una mera aplicación de la legislación contractual. Estamos así ante "una simple norma organizativa dirigida a la entidades y organismos forales que intervienen en la contratación de obras públicas, a modo de común "protocolo de actuación" (...)" y que encuentra su habilitación en el art. 118 TRLCSP (FJ 2, STSJ País Vasco 296/2014). No corre la misma suerte la creación de un órgano -Comisión Técnica de Verificación y Evaluación del cumplimiento de las cláusulas de carácter social-y el correspondiente procedimiento de verificación y evaluación: en este punto

41.- Vgr. IJCCA Aragón 1/2015, de 17 de marzo. Asunto: "Incorporación de cláusulas de contenido social, laboral y medio ambiental en los Pliegos que rigen las licitaciones de los contratos de la Administración de la Comunidad Autónoma de Aragón".

42.- SSTSJ País Vasco núm. 603/2014 de 30 de diciembre de 2014 (recurso núm. 643/2013; RJ 2015/296) y 617/2014, de 30 de diciembre de 2014 (recurso núm. 630/2013; RJ 2015/296). En idéntico sentido y en conflicto sustancialmente igual formulado contra Norma Foral de las Juntas Generales de Álava 1/2014, de 12 febrero, STSJ País Vasco núm. 100/2015, de 4 de marzo de 2015 (recurso núm. 152/2014; RJ 2015/317). 


\section{CONTRATACIONES PÚBLICAS SOCIALMENTE RESPONSABLES: LA NECESIDAD DE RECONSIDERAR EL POTENCIAL DE LA CONTRATACIÓN PÚBLICA EN LA CONSECUCIÓN DE OBJETIVOS SOCIALES}

el Tribunal estima que la Norma foral excede de la mera aplicación, creando ex novo -regulando, en suma- sobre una materia para la que carece de capacidad normativa ${ }^{43}$.

La dificultad de la incorporación obligada de cláusulas sociales es evidente: la vinculación directa al objeto del contrato y las dificultades que entraña este requerimiento se trasladan también aquí, sobre todo cuando lo que se pretende es que determinadas condiciones se incorporen generalizadamente para toda la actividad contractual de una Administración (obviamente el problema desaparece si nos movemos en el terreno de las recomendaciones). GALLEGO CÓRCOLES (2012) considera que reglamentariamente puede establecerse la obligatoriedad de este tipo de cláusulas, aunque la normativa básica estatal haya previsto sólo una posibilidad, entendiendo que se trata de "una cuestión relacionada con el desarrollo normativo de la norma". A nuestro juicio este argumento no es convincente en cuanto el problema no estriba en que estemos ante el desarrollo de la ley por vía reglamentaria, sino en si tal previsión es o no conforme con la legislación contractual y, más concretamente, en si es o no compatible con los principios que presiden aquella.

\section{4.- Acerca de la nueva normativa de contratación pública}

\subsection{Algunos apuntes adicionales sobre la pertinencia de un cambio normativo}

Si antes hemos puesto de relieve que el cambio normativo que se avecina viene impuesto por los plazos de transposición señalados en el paquete de Directivas comunitarias de contratación de 2014 , no podemos obviar que las mismas dan respuesta a las necesidades planteadas desde diversos frentes.

El ya citado Libro Verde sobre la modernización de la política de contratación pública de la UE apuntaba a la pertinencia de incorporar reformas sobre diversos aspectos con el fin, precisamente, de cumplir los desafíos de la EE2020. Con el empeño de evitar tanto nuevas cargas administrativas, como

43.- Estas sentencias cuentan con un voto particular del Magistrado González Sáiz con una serie de argumentos que exponemos de manera resumida: a) Exceso competencial de la norma foral, sin que sea dable entender que estamos ante una norma de autoorganización (sólo factible respecto de materias para las que se tiene competencia, situación que no se da en este caso); b) Norma con efectos ad extra: atendiendo a su contenido no cabe defender que estamos ante una mera norma organizativa, ya que tiene influencia material sobre el desarrollo de los contratos y los propios contratistas; c) Extralimitación competencial, ya que la Norma foral entra en parcelas para las que las Juntas Generales carecen de competencia (legislación de contratos y legislación laboral y de Seguridad Social); d) Falta de competencia de las Juntas Generales que, sin perjuicio de que ostenten el poder normativo, "no pueden regular omnímodamente aspectos que afecten al resto de Instituciones Forales", siendo necesario que estemos ante una competencia foral y que las Juntas se hallen facultadas para regularlas. En este punto el voto particular entiende que las Juntas se han arrogado atribuciones que la normativa contractual asigna exclusivamente al órgano de contratación (como es la determinación de las condiciones de ejecución de carácter social ex art. 118 TRLCSP)

A nuestro juicio, este voto particular es coherente con el fallo de la STSJ País Vasco núm. 344/2014, antes reseñada. 
el falseamiento de la competencia en los contratos públicos, el documento pone de manifiesto las "dos maneras posibles" de realizar los objetivos de aquella:

"Proporcionar a los poderes adjudicadores los medios para tener en cuenta esos objetivos de acuerdo con las normas procedimentales de contratación pública ("cómo comprar»)

Imponer requisitos obligatorios a los poderes adjudicadores o proporcionar incentivos para orientar sus decisiones respecto a qué productos y servicios deben comprarse ("qué comprar»)"

Ciñéndonos al escenario español el reciente informe de la Comisión Nacional de los Mercados y de la Competencia (CNMC) ${ }^{44}$ subraya una serie de aspectos que deben reforzarse en la normativa española aunque, a nuestro juicio, recalcando con inusitada insistencia parámetros de competencia y eficiencia económica. Dicho informe parte de la consideración de que "el sector público en España debe autoimponerse una contratación pública cada vez más transparente, procompetitiva y económicamente eficiente, en beneficio de los ciudadanos, de las empresas y de las propias Administraciones Públicas"45. E identifica una serie de deficiencias en la normativa (y, por tanto, aspectos a mejorar) que, en síntesis, son las que siguen:

a) Mayor acceso, transparencia y publicidad, como medio esencial de aumentar la eficiencia en el aprovisionamiento 46 . Ello deriva tanto en deberes de información y publicidad respecto de todos los procedimientos de licitación (planificados, abiertos o ya desarrollados), como en el fomento de la estandarización de los distintos tipos de contratos y sus correspondientes partidas de gastos.

b) Evaluación de la eficiencia económica y de la competencia efectiva 47 , tanto interna (por parte del órgano de contratación) como externamente. En este punto se pone de relieve que no se lleva a cabo un juicio de la adecuación económica de los procesos seguidos para el aprovisionamiento -esto es, ya contratación, ya encomiendas de gestión ${ }^{48}$-, ni una estimación idónea de los costes incluidos en los presupuestos de licitación (aconsejándose la realización de auditorías de costes)

44.- CNMV (2015), cit.

45.- CNMC, 2015: 4.

46.- CNMC, 2015: 9 a 13.

47.- CNMC, 2015: 13 a 18.

48.- Este tema encierra una complejidad que no podemos abordar aquí, aunque a modo de mero apunte recordaremos que las encomiendas de gestión reguladas en el todavía vigente art. 15 LRJAP-PAC, conducen a la figura conocida como in house providing que, excluida de la normativa contractual, comporta la utilización de medios propios (entes instrumentales) para la prestación de que se trate. Sobre la problemática de esta figura, GIMENO FELIÚ, 2003: 76-83; BURZACO SAMPER, 2012: 1647-1660. Los conflictos sobre esta cuestión han sido muchos, dando lugar a jurisprudencia comunitaria de incuestionable interés que se inicia con la STJUE de 18 de noviembre de 1999 (Asunto C107/1998; Teckal Srl contra Comune di Viano y Azienda Gas-Acqua Consorziale (AGAC) di Reggio Emilia) y prosigue en otras muchas resoluciones judiciales: citando solo algunas, SSTJUE de 13 de octubre de 2005 (Asunto C-458/2003; Parking Brixen GMBH contra Gemeinde Brixen y Stadtwerke Brixen AG), 6 de abril de 2006 (Asunto C-410/2004; Anav contra Comune di Bari y AMTAB Servizio SpA), 19 de abril de 2007 (Asunto C-295-2005; Asociación Nacional de Empresas Forestales (Asemfo) contra Transformación Agraria SA (Tragsa) y Administración del Estado) y, más recientemente, de 8 de mayo de 2014 (Asunto C-15/2013; Asunto: Technische Universität Hamburg-Harburg y HochschulInformations-System GmbH contra Datenlotsen Informationssysteme GmbH) y 19 de junio de 2014 (Asunto C-574/2012; Centro Hospitalar de Setúbal EPE y Serviço de Utilização Comum dos Hospitais (SUCH) contra Eurest (Portugal) - Sociedade Europeia de Restaurantes Lda). Sobre esta última véase el interesante trabajo de TEJEDOR BIELSA, 2015. En cuanto a conflictos resueltos por tribunales españoles, entre otras, STS (Sala 3a) de 20 de marzo de 2012 (recurso núm. 819/2009; EDJ 2012/50114) y de 25 de enero de 2013 (recurso núm. 3351/2010; EDJ 2013/3212). 


\section{CONTRATACIONES PÚBLICAS SOCIALMENTE RESPONSABLES: LA NECESIDAD DE RECONSIDERAR EL POTENCIAL DE LA CONTRATACIÓN PÚBLICA EN LA CONSECUCIÓN DE OBJETIVOS SOCIALES}

Las reformas normativas operadas en octubre de 2015 muestran un viraje hacia la limitación de las encomiendas de gestión, prohibiendo que éstas tengan como objeto prestaciones propias de contratos regulados por la legislación de contratos del sector público 49 .

c) Implementación y aprovechamiento de las tecnologías de información ${ }^{50}$, que según la CNMC deben ser utilizadas "sistemática, exhaustiva y obligatoria[mente]", aprovechando al máximo los sistemas basados en open data ${ }^{51}$ y big data tanto para la eventual mejora económica del aprovisionamiento como para la detección de posibles irregularidades.

d) Mayor cooperación administrativa 52 , tanto horizontal como vertical (entre Administraciones Públicas y en el seno de cada una de ellas), compartiendo información y cumpliendo la obligación existente de remisión de datos.

e) Simplificación de los procedimientos de contratación ${ }^{53}$, que es considerada uno de los ejes fundamentales para el logro de un verdadero espacio europeo de contratación pública en línea con lo pretendido por la EE2020. Ello pasa no sólo por una mayor sencillez de los trámites y requerimientos a los licitadores, sino también por la extensión de los procedimientos electrónicos ${ }^{54}$ y el fomento de la contratación centralizada.

En todo caso estas vías presentan también dificultades: así, en relación con la contratación electrónica se alude a la carencia de interoperatibidad transfronteriza y la complejidad de las interfaces 55 . Por su parte, la agregación de la demanda que comporta la centralización consigue un ahorro constatable pero juega a veces en un difícil equilibrio respecto de ciertos principios de la contratación, señaladamente el de libre concurrencia e igualdad.

49.- Art. 11.1 Ley 40/2015, de 1 de octubre, de Régimen Jurídico del Sector Público.

50.- CNMC, 2015: 18 y 19.

51.- A modo de ejemplo, véase la Web del Ayuntamiento de Bilbao, que incorpora dicho concepto respecto de la actividad contractual (junto con otras informaciones) apuntando "que tiene como misión fundamental contribuir, mediante la publicación progresiva de datos públicos, al desarrollo de los sectores económicos, al fomento de la transparencia administrativa y al avance de smart Bilbao": http://www.bilbao.net/opendata/es/inicio

52.- CNMC, 2015: 19 y 20.

53.- CNMC, 2015: 20 a 24.

54.- Se pone el significativo ejemplo de Portugal que ha desarrollado sistemas electrónicos en una cifra que ronda el $90 \%$, logrando una considerable reducción de los plazos de tramitación y un importante ahorro económico (se aporta la cifra de un ahorro neto de 650 millones de euros en el primer año)

Es indudable que el grado de avance tecnológico actual aconseja avanzar en procedimientos de contratación electrónica tanto por lo que comporta de simplificación y ahorro de costes, como porque favorece una mayor competencia efectiva y abre la contratación pública (no sólo en clave nacional) a un número superior de empresas. Así lo ha reconocido la COMISIÓN EUROPEA. "Estrategia en pos de la contratación pública electrónica" COM (2012) de 20 de abril de 2012.

55.- Tratando de resolver estos problemas se han puesto en marcha algunos proyectos, entre los que destacan el Golden Book of eProcurement Good Practices (Libro de oro de buenas prácticas para la licitación electrónica), y el Expert group on e-Tendering (e-TEG), grupo de expertos que se ha encargado de desarrollar una suerte de esquema-modelo para la fase anterior a la adjudicación La información sobre estos proyectos, puede encontrarse, por orden de mención, en los siguientes enlaces: http://ec.europa.eu/internal_market/publicprocurement/eprocurement/golden-book/index_en.htm y http://ec.europa.eu/internal_market/publicprocurement/e-procurement/expert/index_en.htm (en esta última pueden hallarse las recomendaciones e informes elaborados por el grupo de expertos e-TEG) 
Sin duda el papel que juega el super-regulador y el propio objeto del informe propician esta perspectiva, pero se echa en falta una visión más integral: parece evidente que el ahorro en términos económicos ${ }^{56}$, en cuanto implica una mejor utilización de los recursos públicos, puede favorecer por vía indirecta la inversión social, pero es una deducción que el lector realiza sin sustento en el propio texto. En este sentido resulta un tanto descorazonador advertir esa proyección puramente unidireccional de la contratación pública sin más aspiración aparente que la puramente presupuestaria.

\subsection{El reforzamiento de los aspectos sociales en la nueva normativa de contra- tación: previsiones}

Estando a las puertas de una nueva normativa contractual que transponga las Directivas comunitarias, cumple examinar si las buenas intenciones descritas encuentran traslación cabal en el texto de aquellas:

a) Posicionándose en un sentido negativo -esto es, desde las consecuencias previstas para el eventual incumplimiento de los correspondientes requerimientos normativos de corte ambiental, laboral y social-, el Considerando 40 recalca que el control de su cumplimiento ha de realizarse en las distintas fases del procedimiento de licitación, a saber, al aplicar: i) los principios generales de selección de participantes; ii) los criterios de exclusión; y, iii) las disposiciones sobre ofertas anormalmente bajas.

En esta misma línea, el art. 18.2 Directiva 2014/24/UE establece que "Ios Estados miembros tomarán las medidas pertinentes para garantizar que, en ejecución de los contratos públicos, los operadores económicos cumplen las obligaciones aplicables en materia medioambiental, social o laboral establecidas en el Derecho de la Unión, el Derecho nacional, los convenios colectivos o por las disposiciones de Derecho Internacional medioambiental, social o laboral enumeradas en el Anexo" (en referencia al Anexo 10). Previsión ésta que, su vez, se conecta con el motivo de exclusión de los licitadores en un procedimiento de contratación contemplado en el art. 57.4 y 5 Directiva 2014/24/UE (relativa al incumplimiento de las obligaciones del art. 18.2 referidas)

b) Más problemas plantea el juego de los criterios sociales en un plano proactivo o positivo, aspecto en el que, a nuestro juicio, las novedades son escasas:

En relación con los criterios de adjudicación para evaluar la oferta más ventajosa, se mantiene el sistema de lista ejemplificativa distinguiendo entre un planteamiento de "relación coste-eficacia" y el de "relación calidad-precio"57; ésta última "se evaluará en función de criterios que incluyan aspec-

56.- El informe (CNMC, 2015: 6) evidencia que la ausencia de concurrencia competitiva lleva a desviaciones medias al alza del $25 \%$ del presupuesto de contratación pública, lo que en el caso de España podría cifrarse en aproximadamente 47.500 millones de euros/año (aprox. $4,6 \%$ PIB anual).

57.- En nuestra opinión la obsesión por la novedad que parece mover al legislador se queda muchas veces en los significantes ( $v$. Considerandos 89 y 90 Directiva 2014/24/UE). Sin perjuicio de que puedan incorporar matices antes no expresados, estas locuciones no difieren en sustancia de las subastas y concursos característicos de la legislación contractual hasta la Ley de Contratos del Sector Público de 2007. Sobre esta cuestión, FERNÁNDEZ ACEVEDO y VALCÁRCEL FERNÁNDEZ, 2014: 201-205. 


\section{CONTRATACIONES PÚBLICAS SOCIALMENTE RESPONSABLES: LA NECESIDAD DE RECONSIDERAR EL POTENCIAL DE LA CONTRATACIÓN PÚBLICA EN LA CONSECUCIÓN DE OBJETIVOS SOCIALES}

tos cualitativos, medioambientales y/sociales vinculados al objeto del contrato público de que se trate" (art. 67.2 Directiva 2014/24/UE) ${ }^{58}$.

Por lo que concierne a las condiciones de ejecución del contrato de carácter social, el art. 70 Directiva 2014/24/UE no trae tampoco nada nuevo, permitiendo que los poderes adjudicadores establezcan aquellas "siempre que estén vinculadas al objeto del contrato (...) y se indiquen en la convocatoria de licitación o en los pliegos de la contratación", pudiendo ser "económicas o relacionadas con la innovación, consideraciones de tipo medioambiental, social, o relativas al empleo".

Otros apartados introducen cambios solo parciales respecto de las previsiones que hoy recoge el TRLCSP: por ejemplo, los contratos reservados a talleres protegidos o centros especiales de empleo ya comentados (art. 20 Directiva 2014/24/UE).

Estas previsiones sobre aspectos sociales y medioambientales encuentran algunos matices que los considerandos de la Directiva se encargan de especificar:

En primer lugar, y pese a la relevancia del papel de la contratación pública para la consecución de los objetivos de la EE2020 (singularmente en el impulso a la innovación), se estima que las grandes diferencias entre los sectores y mercados no permiten imponer a la contratación requisitos medioambientales, sociales y de innovación "de carácter general y obligatorio" (Considerando 95).

Se aclara que la contratación pública estratégica comporta que los poderes adjudicadores puedan determinar la oferta más ventajosa con base en el llamado "coste del ciclo de la vida"59. Precisamente este concepto sive de enlace con la posible incorporación de consideraciones sociales y medioambientales como criterios de adjudicación o condiciones de ejecución respecto de obras, suministros o servicios facilitados en el marco de un contrato público "incluso cuando dichos factores no formen parte de su sustancia material" (p.ej. utilización de productos procedentes del comercio justo) (Considerando 97).

A otra conclusión se llega en relación con algunos aspectos que la Directiva traba a circunstancias subjetivas de las empresas licitadoras. Singular interés tiene la referencia a la responsabilidad social corporativa, que queda excluida expresamente al no entenderse como un factor característico del proceso específico de producción o prestación de obras, suministros o servicios. De este modo "los poderes adjudicadores no pueden estar autorizados a exigir a los licitadores que tengan establecida una determinada política de responsabilidad social o medioambiental de la empresa" (Considerando 97).

58.- El apartado a) del mencionado art. 67.2 Directiva 2014/24/UE alude expresamente a las "características sociales", bien es cierto que dentro de un listado que es un totum revolutum en el que se integran la calidad, el valor técnico, las características estéticas y funcionales,...

59. - Esta noción "incluye todos los costes a lo largo del ciclo de vida de las obras, suministros o servicios", tanto los costes internos (p.ej. investigación), como de desarrollo, producción, transporte, uso, mantenimiento y eliminación al final de la vida útil, pudiendo incluirse también costes relativos a factores medioambientales externos (ver Considerando 96 en el que se desarrolla esta referencia). Acerca del cálculo del coste del ciclo de vida, art. 68 Directiva 2014/24/UE. 
Se contempla la posibilidad de que los poderes adjudicadores exijan etiquetas específicas (en las especificaciones técnicas, en los criterios de adjudicación o en las condiciones de ejecución del contrato) cuando adquieran obras, suministros o servicios "con características específicas de tipo medioambiental, social u otro". Dicha etiqueta actúa como medio de prueba de que aquellas se corresponden con las características exigidas y ha de cumplir las condiciones establecidas en el art. 43.1 Directiva 2014/24/UE (art. 127 Anteproyecto).

Todos los aspectos anotados se reflejan en el borrador de Anteproyecto de Ley de Contratos del Sector Público que recoge asimismo determinados puntos que pueden jugar en favor de una mayor impronta social. Casi telegráficamente, destacaremos:

i) Se amplía el abanico de criterios de desempate susceptibles de incorporarse a los PCAP, incluyendo empresas de inserción, entidades sin ánimo de lucro (éstas últimas en relación con prestaciones de carácter social o asistencial) y empresas que, al acreditar su solvencia, incluyan medidas favorecedoras de la igualdad de oportunidades entre mujeres y hombres (art. 145.9). En similar línea, se prevén los criterios de desempate caso de que los pliegos no los contemplen, todos ellos de componente social (art. 145.10)

ii) También se completa la normativa anterior en cuanto a las condiciones especiales de ejecución de carácter social incluyendo nuevas opciones (art. 200.2)

iii) Una de las líneas esenciales de la reforma se centra en potenciar el acceso a las PYME a la contratación pública mediante medidas de muy diverso signo: simplificación de trámites y procedimientos, inversión de la regla general sobre la división en lotes de los contratos 60 (art. 99.3), mayor protección al subcontratista (arts. 196.7 y 215),...

MARTÍNEZ FERNÁNDEZ (2015: 2) ha resaltado que el Anteproyecto avanza en la inclusión obligatoria de consideraciones sociales en los contratos públicos y aboga por cambiar la locución relativa a la adjudicación de los contratos incorporando el elemento social, esto es, imponer la adjudicación a la "oferta económica y socialmente más ventajosa".

Hay que decir que las Administraciones Públicas españolas han sido sensibles a la incorporación de cláusulas sociales en su correspondiente actividad contractual, si bien se advierte cierta distancia temporal en su instrumentación jurídica61. Destacan también las Guías para la inclusión de cláusulas sociales 62 .

60.- Esta previsión conectada con otras de las que hemos destacado, extiende la posibilidad de que la contratación pública llegue a más empresas y singularmente a las que presentan más dificultades para competir en el mercado. Así lo evidencia la Disposición Adicional $4^{a}$ Anteproyecto respecto de los contratos reservados. 


\section{CONTRATACIONES PÚBLICAS SOCIALMENTE RESPONSABLES: LA NECESIDAD DE RECONSIDERAR EL POTENCIAL DE LA CONTRATACIÓN PÚBLICA EN LA CONSECUCIÓN DE OBJETIVOS SOCIALES}

\subsection{La vinculación al objeto del contrato y los criterios sociales}

El examen del papel de los criterios sociales en la contratación pública pone de relieve la existencia de diversos escollos que están dificultando que alcancen plena virtualidad. De entre ellos posiblemente el más relevante sea el requisito de la vinculación al objeto del contrato; exigencia que aparece insistentemente respecto de los distintos elementos de la contratación analizados (condiciones subjetivas de solvencia de las empresas licitadoras, criterios de adjudicación, condiciones especiales de ejecución,... $)^{63}$.

La recurrencia en la "vinculación al objeto del contrato" encuentra su razón de ser en las siguientes razones 64 :

a) Asegura el uso eficiente de los fondos públicos al permitir comprar al mejor precio, lo que, a su vez, garantiza la coherencia entre las políticas de contratación pública y las normas en materia de ayudas públicas.

61.- La Comunidad Autónoma vasca fue una de las primeras en hacerlo mediante Resolución 6/2008, de 2 de junio, del Director General de la Secretaría del Gobierno y de Relaciones con el Parlamento, por la que se aprueba la Instrucción para la incorporación de criterios sociales, medioambientales y derivados de otras políticas públicas en la contratación de la Administración de la Comunidad Autónoma y sus entidades del sector público (BOPV núm. 116, de 19 de junio de 2008). De acuerdo con punto cuarto del Acuerdo, el contenido de la Instrucción se incorporará a los modelos tipo de pliegos de cláusulas administrativas particulares (aprobados por Acuerdo del Consejo de Gobierno de 22 de mayo de 2007; BOPV núm. 246, de 24 de diciembre de 2007). A partir de ahí se han ido sucediendo otras iniciativas que, por orden cronológico, son las siguientes:

- Castilla y León: Acuerdo 59/2012, de 26 de julio de la Consejería de Hacienda de la Comunidad Autónoma de Castilla y León por el que se aprueban directrices vinculantes para los órganos de contratación de la Administración de la Comunidad de Castilla y León sobre incorporación de cláusulas sociales en la contratación pública (BOCL núm. 147, de 1 de agosto de 2012)

- Principado de Asturias: Acuerdo del Consejo de Gobierno de 29 de mayo de 2013 por el que se aprueban modelos de cláusulas sociales en el ámbito de la contratación pública (BOPA núm. 130, de 6 de junio de 2013)

- Extremadura: Resolución de 1 de agosto por la que se dispone la publicación del Acuerdo del Consejo de Gobierno de 8 de julio de 2014 , por el que se aprueban las directrices de política general dirigidas a los órganos de contratación de la Administración de la Comunidad Autónoma de Extremadura sobre contratos reservados e incorporación de cláusulas sociales en la contratación pública (DOE núm. 150, de 5 de agosto de 2014)

- Navarra: Ley Foral 1/2015, de 22 de enero, por la que se modifica la Ley Foral 6/2006, de 9 de junio, de Contratos Públicos, para la introducción de cláusulas sociales en los pliegos de cláusulas administrativas (BON núm. 21, de 2 de febrero de 2015). Uno de los preceptos de esta reforma (concretamente la modificación del art. 49 de la Ley Foral relativo a los requerimientos de carácter social y ambiental en la ejecución de contratos) ha sido motivo de discrepancias entre la Comunidad Foral y la Administración General del Estado. Ambas Administraciones han iniciado negociaciones sobre el particular: véase, Resolución de 30 de abril de 2015, de la Secretaría General de Coordinación Autonómica y Local, por la que se publica el Acuerdo de la Junta de Cooperación Administración General del Estado-Comunidad Foral de Navarra en relación con la Ley Foral 1/2015, de 22 de enero, por la que se modifica la Ley Foral 6/2006, de 9 de junio, de Contratos Públicos, para la introducción de cláusulas sociales en los pliegos de cláusulas administrativas (BOE núm. 118, de 18 de mayo de 2015)

- Comunidad Valenciana: Acuerdo del Consell de la Generalitat Valenciana de 27 de marzo de 2015, por el que se establecen directrices para la aplicación de cláusulas de carácter social en la contratación de la Administración de la Generalitat y su sector público, así como en materia de subvenciones de la Administración de la Generalitat (DOCV núm. 7498, de 2 de abril de 2015)

También en el nivel local pueden encontrase interesantes iniciativas. Describe algunas de ellas BERNETE GARCIA, 2013: 90-93.

62.- Guía para la inclusión de cláusulas contractuales de carácter social (Barcelona, marzo 2010), elaborada por la Junta Consultiva de Contratación Administrativa de la Generalidad de Cataluña. Disponible en: http://www.conr.es/descargas/Gu\%C3\%ADa\%20Cl\%C3\%A1usulas\%20Sociales\%20Catalu\%C3\%B1a.pdf

63.- Acerca del protagonismo de este elemento, BERNAL BLAY, 2011: 148-149.

64.- Sintetizamos a continuación los elementos nucleares del Libro Verde (COM (2011): 42-43. 
b) Evita el favorecimiento de operadores económicos de determinados países en detrimento de los de otros Estados miembros.

c) Aporta seguridad y previsibilidad a las empresas, especialmente a las PYME, evitando que cada contratación o cada poder adjudicador multiplique requisitos específicos.

d) Obviar la vinculación al objeto del contrato podría obstaculizar el objetivo de EE2020 de promover la innovación.

Sin negar sentido a las razones expuestas, no es menos cierto que este requerimiento implica una restricción importante para que las cláusulas sociales jueguen un papel relevante y es, probablemente, el motivo de los alardes imaginativos que algunos órganos de contratación están mostrando65. El propio Libro Verde lo asegura cuando confiesa que la flexibilización de este requisito permitiría avanzar en la realización de los objetivos políticos de Europa 2020 a través de la contratación pública66.

En este punto la Directiva 2014/24/UE incluye novedosamente una "cierta" conceptuación de qué se entiende por vinculación al objeto del contrato por lo que respecta a los criterios de adjudicación:

Art. 67.3. "Se considerará que los criterios de adjudicación están vinculados al objeto del contrato público cuando se refieran a las obras, suministros o servicios que deban facilitarse en virtud de dicho contrato, en cualquiera de sus aspectos y en cualquier etapa de su ciclo de vida, incluidos los factores que intervienen:

a) en el proceso específico de producción, prestación o comercialización de las obras, suministros o servicios, 0

b) en un proceso específico de otra etapa de su ciclo de vida, incluso cuando dichos factores no formen parte de su sustancia material".

Indudablemente esta noción es lo suficientemente imprecisa para aventurar la importancia de la interpretación del TJUE sobre la misma. No obstante parece vislumbrarse una mayor amplitud comparativamente a la que ha venido defendiéndose hasta el momento y que requería que dicha vinculación fuera directa. A nuestro juicio el mencionado art. 67.3 in fine de la Directiva -"...incluso cuando dichos factores no formen parte de su sustancia material"- así lo permite.

En todo caso, esta cuestión pone de manifiesto el problema esencial de las cláusulas sociales en la contratación pública y es que aquellas actúan en un plano distinto en la medida en que obedecen

65.- Recoge diversos ejemplos BERNETE GARCÍA, 2013: 90-92. Con él ánimo de salvar este requerimiento, PANIAGUA ZURERA (2013: 205), aboga por que en la delimitación del objeto del contrato se realice una referencia "directa y expresa", p.ej., a la inserción sociolaboral de colectivos desfavorecidos.

66. - Se constata cómo "entre otras cosas, permitiría a los poderes adjudicadores influir en los comportamientos de las empresas con independencia del producto o servicio adquiridos, por ejemplo, para fomentar una mayor responsabilidad medioambiental o una mayor atención a la responsabilidad social corporativa. Este podría ser un poderoso instrumento en apoyo de los objetivos políticos de la estrategia Europa 2020" [Libro Verde (COM (2011): 42]. 


\section{CONTRATACIONES PÚBLICAS SOCIALMENTE RESPONSABLES: LA NECESIDAD DE RECONSIDERAR EL POTENCIAL DE LA CONTRATACIÓN PÚBLICA EN LA CONSECUCIÓN DE OBJETIVOS SOCIALES}

a finalidades que se apartan del fin propio del contrato 67 . Esta diversidad de fines explica el freno permanente para encontrar vías de coincidencia, actuando a veces incluso como antagonistas ${ }^{68}$. Traba que no se resolverá en tanto las autoridades competentes no sean conscientes de la necesidad de flexibilizar ciertos requerimientos para actuar con proyección integral y sin perder de vista que el mandato constitucional del art. 103 CE -amén de otros muchos preceptos constitucionales (arts. 9.2, 53.3 $\mathrm{CE}, \ldots)$ - no permite relegar los objetivos sociales a un papel de mera guarnición.

Fijémonos en que el argumento para no establecer preceptivamente requisitos sociales, ambientales 0 de innovación se centra en las "grandes diferencias existentes entre los distintos sectores y mercados"; diferencias que, por lo demás, ha ahondado la crisis económica y que, a nuestro juicio, reclamarían una acción más intensa de los Estados en defensa de los intereses generales; en suma, del bien común69.

67.- Es significativa en este punto la respuesta del TSJ País Vasco en uno de los casos ya comentados. A la alegación de desviación de poder el Tribunal responde: "La desviación de poder no puede ser advertida en tales circunstancias no exentas de abstracción, pues el hecho de que las condiciones o cláusulas de carácter social consagradas por el articulo 118 TRLCSP se ordenen a fines que no sean los estrictamente ceñidos al cumplimiento del contrato en cualquier modo y manera, es consustancial a las mismas y su razón de ser a partir de su reconocimiento legal y por convenios internacionales y directivas comunitarias, que las conciben como medidas de política social y medioambiental que concurren con el objeto estricto de la ejecución de la obra o la prestación del servicio, de manera tal que no cabe afirmar que el establecimiento de las penalidades previstas por el articulo 118.2 en relación con el art. 212 TRLCSP, o que estas se configuren mediante tipificaciones y listados de las mismas, con diferente calificación y consecuencias contractuales, se erija en la manifestación de una finalidad desviada de dichas cláusulas tendente a ejercitar potestades de inspección y sanción laboral paralela al funcionamiento de otras instituciones públicas que las ejercen con carácter general y sin consideración a la relación especial reinante entre las partes contratantes que las suscriben mediante un contrato". STSJ País Vasco 617/2014, de 30 de diciembre (cit.), FJ $5^{\circ}$.

68.- DOMÉNECH PASCUAL (2012: 42) evidencia que no puede discutirse que las Administraciones públicas hayan de adoptar medidas conducentes a objetivos sociales o de protección medioambiental, pero pone igualmente el acento en que "los poderes públicos también deben ponderar otros bienes jurídicos constitucionales afectados por su actividad contractual, tales como la libertad de empresa, la igualdad de trato entre los candidatos, la libre competencia y la eficiente utilización de los fondos públicos" y siendo que "las medidas de protección medioambiental y social suelen tener un coste para los referidos derechos y, en última instancia, para los fondos públicos" se impone llegar "a una solución equilibrada, proporcionada, que no restrinja inútil, innecesaria o excesivamente la libertad de los ciudadanos, ni represente un gasto ineficiente de dinero público. El objetivo debería ser alcanzar el nivel deseado de protección medioambiental y social con el menor coste posible para la libertad y el erario público 0 , si se quiere, alcanzar el mayor grado de esa protección con los recursos que estemos dispuestos a invertir en ella".

Aunque sin profundizar en la cuestión en Dictamen CES 8/2015 muestra sus cautelas sobre la inclusión de este tipo de medidas como criterios de adjudicación por su posible impacto sobre las PYME (p. 13).

69.- Aunque no es objeto central de este trabajo no podemos olvidar la reflexión sobre la reforma del Estado que está llevándose a cabo por reputados académicos de Derecho Público y que elevan sus voces sobre la conveniencia de reivindicar el papel del Estado en su defensa del interés general frente a la incapacidad de la sociedad por definirlo y el creciente poder de determinados sujetos privados. Especialmente enriquecedor ha sido el Seminario sobre la reforma del Estado organizado por el Instituto Nacional de Administración Pública (INAP) y dirigido por el profesor MUÑOZ MACHADO y cuyas conclusiones e intervenciones de los participantes han sido resumidas y publicadas por GARCIA ROCA y ESTEVE PARDO (2014).

CIRIEC-España, Revista de Economía Pública, Social y Cooperativa

ISSN: 0213-8093

№ $86 / 2016$, pp. $281-310$ 


\section{5.- Conclusiones e incógnitas}

Las técnicas de intervención administrativa se caracterizan por el principio de intercambiabilidad, de modo que el objetivo a perseguir, el fin de interés general que ha de estar en la base de la actuación de las Administraciones Públicas, puede alcanzarse a través de distintos instrumentos. En este punto creemos que no puede discutirse que la contratación pública puede servir para orientar la actividad económica hacia fines sociales de modo tanto o más eficaz que otros instrumentos jurídico-públicos (señaladamente subvenciones, ayudas y los que, en general, entran en la tradicional categoría de fomento ${ }^{70}$ ).

Ahora bien, lo cierto es que este potencial no ha terminado de cuajar por diversas razones, algunas de las cuales tienen que ver con la difícil conciliación entre determinados elementos de la contratación (señaladamente los principios) y su manera de conjugarse. La propia "ubicuidad" de los criterios sociales ha terminado por trocarse en un auténtico problema de "ubicación": y ello porque al margen de la mayor o menor idoneidad del juego de las cláusulas sociales en uno u otro lugar del contrato, los obstáculos son, en el fondo, si no los mismos, sí muy similares. Por poner un ejemplo: ¿cuál es realmente el hándicap que debe salvar un criterio de adjudicación de impronta social para entenderse válido? La vinculación con el objeto del contrato, amén de la no vulneración de los principios de la contratación -especialmente importantes en este punto, los principios de igualdad y libre concurrencia-. ¿Qué hacemos cuando ese mismo requisito se exige cuando hablamos de establecer criterios de solvencia y condiciones especiales de ejecución? ¿No nos encontramos, acaso, en el mismo punto y con el mismo obstáculo?

La posición central de los principios y su fundamental papel como parámetro de control está fuera de cuestión, aunque debemos admitir que la mayor parte de ellos se escoran hacia el lado puramente económico de la contratación. Desde este punto de vista, el cumplimiento de objetivos sociales a través de la contratación pública encuentra escollos que suelen sortearse con buenas palabras de escasa practicidad. Una suerte de cuadratura del círculo, donde se quiere incluir cláusulas sociales que, además, no enturbien el sacrosanto mercado y la libre competencia, única que, por lo que se ve, alcanza las cotas deseadas de eficiencia económica ${ }^{71}$.

70.- Sobre esta cuestión resulta reveladora la obra de HUERGO LORA, 1998: 183, en especial nota al pie núm. 125.

71.- PANIAGUA ZURERA (2013: 181) denuncia con acierto cómo el pensamiento neoliberal enfoca la innovación social a la luz de un único criterio de valoración que no es otro que la eficiencia económica referida estrictamente a la obtención de beneficios económicos. 


\section{CONTRATACIONES PÚBLICAS SOCIALMENTE RESPONSABLES: LA NECESIDAD DE RECONSIDERAR EL POTENCIAL DE LA CONTRATACIÓN PÚBLICA EN LA CONSECUCIÓN DE OBJETIVOS SOCIALES}

Tal vez, entonces, debamos plantearnos si para nuestros legisladores (incluyendo obviamente al comunitario) la eficiencia social no lo es también económica; porque, como subraya GIMENO FELIÚ (2014: 18), el principio de eficiencia requiere salir de la mera perspectiva económica imperante y conectar el empleo de fondos públicos con objetivos sociales, ambientales o de investigación.

En las Directivas de cuarta generación hay elementos que permiten aventurar un cambio que, sin embargo, no será de calado mientras se mantengan algunas de las actuales pautas. En nuestra opinión podría ganarse terreno a través de diversas vías:

a) Determinando con claridad el espacio en que deben ubicarse las cláusulas sociales y abriendo la posibilidad a su establecimiento obligatorio en toda la actividad contractual de los órganos de contratación.

b) Eliminando la rigidez que implica la vinculación al objeto del contrato, evitando adjetivar dicha vinculación de "directa" y pasando a interpretarla en términos más amplios. Ello abriría posibilidades de que el concepto de interés general penetrara en la contratación pública, sin necesidad de buscar recovecos por los que colar este tipo de objetivos.

c) Habría que realizar evaluaciones a posteriori de lo que las normas y medidas comportan. Volvemos así a la permanente asignatura pendiente del legislador español: presupuesta la buena intención de las reformas normativas y de las políticas públicas que llevan aparejadas, campa después la más absoluta despreocupación por conocer el efecto real de las mismas, su coste, el cumplimiento (o no) de las expectativas, etc. Y conviene no olvidar que el análisis de impacto es ingrediente ineludible de la llamada "Normativa Inteligente", también conectada con la EE202072.

Al tiempo de escribir estas líneas se ha publicado la Recomendación del Consejo de la Unión Europea $2015 / 1184$, de 14 de julio de $2015^{73}$, relativa a las orientaciones generales para las políticas económicas de los Estados miembros y de la Unión Europea. Entre otras cosas, señala que "el principal desafío al que hemos de hacer frente hoy consiste en llevar a la Unión a una situación de crecimiento inteligente, sostenible e integrador y de creación de empleo" (Considerando 3) y continúa diciendo:

72.- Conviene aclarar que la Normativa inteligente se refiere "al conjunto del ciclo político, desde la concepción del acto legislativo hasta la aplicación, el cumplimiento, la evaluación y la revisión" [COMISIÓN EUROPEA. Comunicación de la Comisión al Parlamento Europeo, al Consejo, al Comité Económico y Social Europeo y al Comité de las Regiones. "Normativa Inteligente de la Unión Europea". COM (2010) 543 final] y subraya la importancia de la calidad de las normas como elemento esencial para la consecución de los objetivos de la EE2020. Para un análisis más detallado de esta cuestión nos remitimos a nuestro trabajo BURZACO SAMPER, 2013 y bibliografía allí citada.

73. - DOUE núm. L 192/27. 
"Los Estados miembros y la Unión deben afrontar también el impacto social de la crisis y fijarse el objetivo de construir una sociedad cohesionada en la que se capacite a las personas para anticipar y gestionar el cambio y participar activamente en la vida social y económica. Es necesario garantizar el acceso y las oportunidades para todos y reducir la pobreza y la exclusión social, principalmente velando por un funcionamiento eficaz de los mercados de trabajo y los sistemas de bienestar social, y eliminando los obstáculos a la participación en el mercado de trabajo. Los Estados miembros deben procurar, asimismo, que los beneficios del crecimiento económico lleguen a todos los ciudadanos y a todas las regiones" (Considerando 4).

Afrontar este mandato con seriedad requiere que las Administraciones empleen todo el instrumental del que disponen. Y, sin duda, la contratación pública es uno de los más poderosos.

\section{6.- Bibliografía}

BERNAL BLAY, M.A. (2008): "Hacia una contratación pública socialmente responsable: las oportunidades de la Ley 30/2007, de 30 de octubre, de Contratos del Sector Público". En: Gimeno Feliu, J.M. (Ed.), El Derecho de los Contratos del Sector Público, Monografías de la Revista Aragonesa de Administración Pública, núm. X, Zaragoza, 211-252.

BERNAL BLAY, M.A. (2011): "El principio de objetividad en la contratación pública", Documentación Administrativa, 289, 129-150.

BERNETE GARCIA, J. (2013): "Cláusulas sociales en la contratación pública: nuevos instrumentos para el fomento del empleo a nivel local", Cuadernos de Trabajo Social, 26-1, 85-94.

BURZACO SAMPER, M. (2010): "La adjudicación de los contratos administrativos: naturaleza de las operaciones implicadas y control judicial", Asamblea, Revista parlamentaria de la Asamblea de Madrid, 23, 171-198.

BURZACO SAMPER, M. (2012): "La contratación pública de los entes institucionales y su control jurisdiccional: apuntes sobre algunos aspectos problemáticos". En: AAVV, Retos de la Abogacía ante la sociedad global, Cizur Menor (Navarra): Civitas/Universidad Pontificia Comillas, 1647-1660.

BURZACO SAMPER, M. (2013): "Calidad de las normas y regulación económica: maridaje imperfecto y búsqueda de soluciones". En: AAVV, Globalización y Derecho: desafíos y tendencias, Bilbao: Universidad de Deusto. 


\section{CONTRATACIONES PÚBLICAS SOCIALMENTE RESPONSABLES: LA NECESIDAD DE RECONSIDERAR EL POTENCIAL DE LA CONTRATACIÓN PÚBLICA EN LA CONSECUCIÓN DE OBJETIVOS SOCIALES}

BURZACO SAMPER, M. (2015): "Los principios de libre concurrencia e igualdad en la contratación pública. Un estudio a la luz de los conflictos". En: Serrano Acitores, A. (Dir.), La intervención administrativa y económica en la actividad empresarial. Barcelona: Bosch, 223-255.

DOMÉNECH PASCUAL, G. (2012): "La valoración de las ofertas en el Derecho de los contratos públicos", Revista General de Derecho Administrativo, 30, 1-59.

FERNÁNDEZ ACEVEDO, R. \& VALCÁRCEL FERNÁNDEZ, P. (2014): "Análisis de los criterios de adjudicación de los contratos públicos en el marco de la cuarta generación de Directivas del sector". En: R. Fernández \& P. Valcárcel (Dirs.), La contratación pública a debate: presente y futuro, Cizur Menor (Navarra): Ministerio de Economía y Competitividad/Civitas Thomson Reuters, 199274.

FERNÁNDEZ ASTUDILLO, J.M. (2005): Los procedimientos de adjudicación de los contratos públicos de obras, de suministro y de servicios en la Unión Europea. La nueva Directiva reguladora de los contratos públicos, Barcelona: Bosch.

GALLEGO CÓRCOLES, I. (2011): "Cláusulas sociales, contratación pública y jurisprudencia del TJUE”, Contratación Administrativa Práctica, 113, La Ley 17357/2011.

GALLEGO CÓRCOLES, I. (2012): “¿Pueden incluirse cláusulas sociales en la contratación pública (y II)?”, Contratación Administrativa Práctica, 116. Ejemplar consultado en: http://revistas.laley.es/content/Revista.aspx?params=H4sIAAAAAAAEAO29B2AcSZYIJi9tynt_SvVK1B0oQiAYBMk2JBAEOzBiM3mkuwdaUcjKasqgcpIVmVdZ

GARCÍA ROCA, J. \& ESTEVE PARDO, J. (2014): "Algo estamos haciendo mal", El País, 20 de febrero, http://elpais.com/elpais/2014/02/18/opinion/1392740983_793385.html

GIMENO FELIU, J.M. (2003): Contratos públicos, ámbito de aplicación y procedimiento de adjudicación: (la incidencia de las directivas comunitarias en el ordenamiento jurídico español), Madrid: Civitas.

GIMENO FELIU, J.M. (2013): "Las nuevas Directivas -cuarta generación- en materia de contratación pública. Hacia una estrategia eficiente de compra pública", Revista española de Derecho Administrativo, 159. Referencia Bibliográfica Aranzadi Insignis (en adelante, BIB) 2013/1529.

GIMENO FELIU, J.M. (2014): El nuevo paquete legislativo comunitario sobre contratación pública. De la burocracia a la estrategia, Cizur Menor (Navarra): Thomson Aranzadi/Ministerio de Economía y Competitividad/ Universidad de Zaragoza.

HUERGO LORA, A. (1998): Los contratos sobre los actos y las potestades administrativas, Madrid: Civitas/Universidad de Oviedo.

LESMES ZABALEGUI, S. (2005): "Contratación pública y discriminación positiva. Cláusulas sociales para promover la igualdad de oportunidades entre mujeres y hombres en el mercado laboral", Lan harremanak. Revista de Relaciones Laborales, 13, 53-86. 
MARTÍNEZ FERNÁNDEZ, J.M. (2015): "Avanzando en Contratación socialmente responsable: de la recomendación a la obligación", Observatorio de Contratación Pública. Sección Opinión (fechado 22/06/2015). Disponible en: http://www.obcp.es/index.php/mod.opiniones/mem.detaIle/id.199/relcategoria.208/relmenu.3/chk.c5bde66cf07d647d9f2f3a90febac2d2

MARTÍNEZ FONS, D. (2009): Cláusulas sociales, libre competencia y contratación pública, Madrid: Fundación Alternativas.

MEDINA ARNÁIZ, T. (2010): "La igualdad de género entre los criterios de adjudicación de un contrato público. Comentario a la Sentencia del Tribunal Superior de Justicia de Extremadura núm. 535/2009, de 16 de junio", Actualidad Jurídica Aranzadi, 794, BIB 2010/254.

MEDINA ARNÁIZ, T. (2012): "La contratación pública socialmente responsable a través de la jurisprudencia del Tribunal de Justicia de la Unión Europea", Revista Española de Derecho Administrativo, 153, 1-20, BIB 2012/241.

MEDINA ARNÁIZ, T. (2015): “¿Es posible la incorporación del comercio justo a los contratos públicos?", Observatorio de Contratación Pública (Sección Opinión). Disponible en: http://www.obcp.es/index.php/mod.opiniones/mem.detalle/id.190/relcategoria.208/relmenu.3/chk.3a7f345 c325afcb57369ff112188c155

PANIAGUA ZURERA, M. (2013). "Las empresas de inserción sociolaboral y las cláusulas sociales en la contratación pública: dos instrumentos necesarios para la innovación social hacia el desarroIlo", REVESCO, Revista de Estudios Cooperativos, 112 (Núm. extraordinario en homenaje al Profesor Alfonso Carlos Morales Gutiérrez), 176-212.

RODRÍGUEZ MUÑOZ, J.M. (2011): "Las políticas públicas de fomento de la responsabilidad social empresarial: a propósito de la innovadora iniciativa legislativa de la comunidad autónoma de Extremadura", Revista Aranzadi Doctrinal, 7/2011, 1-24, BIB 2011/1601.

SÁNCHEZ GIL, I. (trad.) (2009): La integridad en la contratación pública. Buenas prácticas de la $\mathrm{A}$ a la Z, Madrid: INAP/OCDE.

SÁNCHEZ MORÓN, M. (2012): "Discriminación positiva por razón de género y adjudicación de contratos públicos", Justicia Administrativa, 58, 7-16.

TEJEDOR BIELSA, J. (2015): "Entidades sin ánimo de lucro, contratos "in house" y reserva legal de contratos", Observatorio de Contratación Pública (Sección Opinión), fecha: 26/01/2015.

Ejemplar consultado en:

http://www.obcp.es/index.php/mod.opiniones/mem.detalle/id.184/relcategoria.208/relmenu.3/chk .0710904471eac90f5835cf55917c4c42

ZÚÑIGA RIAL, G. (2008): "El tratamiento de las cláusulas sociales en la normativa reguladora de la contratación pública. Su consideración como criterios de adjudicación de los contratos administrativos", Dereito, 17 (2), 65-90. 